\title{
In memoriam: Ali Hasan Nayfeh 1933-2017
}

\author{
M. I. Younis
}

Published online: 12 May 2017

(C) Springer Science+Business Media Dordrecht 2017

On March 27, the nonlinear dynamics, vibration and control, and applied mathematics communities lost a pioneer scientist and one of the most influential scholars over the past five decades, University-distinguished emeritus Professor Ali Hasan Nayfeh, who passed away suddenly in Amman, Jordan, at the age of 83.

Nayfeh was born in a small village in Palestine, Shuwaikah, in 1933 to illiterate parents and a poor family. His parents nevertheless highly valued education and encouraged their oldest son Ali to acquire the maximum knowledge that he could achieve. At the final high school year, in which students are subjected to national standardized examinations, Nayfeh ranked remarkably sixth among all the students in Jordan and Palestine, which was an early sign of his brilliance. However, due to the harsh conditions and lack of higher-education institutes at the time, Nayfeh had to work as a school teacher teaching mathematics in remote villages and towns, during which he kept searching for an opportunity to continue his education. At that point, the reputation of Nayfeh was spreading around in the cities and villages of Jordan and Palestine as a genius and a go-to math wizard.

\footnotetext{
M. I. Younis ( $\square)$

Department of Mechanical Engineering, State University of New York at Binghamton, 4400 Vestal Parkway East, Binghamton, NY 13902, USA

e-mail: myounis@binghamton.edu

M. I. Younis

Physical Science and Engineering, King Abdullah University of Science and Technology KAUST, Thuwal, Saudi Arabia
}

After 10 years of working as a teacher, the opportunity came and Nayfeh got a scholarship to study in the USA, in 1959. He spent a year at San Mateo Junior College, then moved to Stanford, where remarkably after a year and a half, he finished his Bachelor's Degree in engineering science with great distinction. A year later, he received a Master of Science degree, and another year later, a $\mathrm{PhD}$, all in aeronautics and astronautics. His graduate research work laid the foundation for his seminal works in perturbation techniques, and especially the method of multiple scales, which he developed to a great depth.

Afterward, Nayfeh worked in the aerospace industry for seven years, while at the same time developing further his perturbation techniques and applying them to various fields in physics and engineering. In 1971, Nayfeh joined Virginia Tech as a Professor, and five years later was named a University Distinguished Professor.

Nayfeh's contribution to science has been immense and at all scales and levels. He authored ten books in nonlinear dynamics and perturbation methods. Several of them have been cited tens of thousands of times and became the most respected and fundamental references in their fields; translated into many languages including Russian, Chinese, and German; and used as core textbooks in top schools. He wrote more than 480 articles in referred journals and contributed more than 36 book chapters. He also founded and served as Editor-in-Chief for two prestigious journals: Nonlinear 
Dynamics and the Journal of Vibration and Control. Nayfeh advised more than $69 \mathrm{PhD}$ students, many of whom became prominent scholars, department chairs and deans in top ranked institutes around the globe.

Nayfeh also took care of his family. He guided and helped his brothers to follow his steps, and all three of them became prominent professors in the USA. His four sons followed on the family tradition earning $\mathrm{PhDs}$ in engineering (with his son Tariq adding in addition a medical degree to become a surgeon). His grandchildren and siblings have been following his steps as well tallying more than $13 \mathrm{PhDs}$ so far.

In addition to the influence of his seminal papers and books; Nayfeh's had also tremendous direct influence in many parts of the world. In 1976, Nayfeh led a group of scientists to establish the college of engineering at King Abdel Aziz University in Jeddah in Saudi Arabia. In 1980 Nayfeh took a leave of absence to establish an engineering college in Jordan and served as its dean, and as vice-president for engineering affairs at the university for four years. In 2002, Nayfeh helped establish a new graduate and internationally reputable program in Mechanics in Tunisia. In his final years after retiring from Virginia Tech, Nayfeh volunteered to work at the University of Jordan, where he helped scientists and researchers and provided valuable advice and consultations. Last but not least, Nayfeh established and fully funded a modern school in his birth village of Shuwaikah, Palestine, to offer the best education and produce the next generation of brilliant scientists.

Nayfeh has been recognized in the scientific community with several awards (more than 30). The most notable of these came in 2014, when he received the Benjamin Franklin Medal in Mechanical Engineering, the highest award in engineering (equivalent to the Nobel Prize in science) putting Nayfeh in the company of the likes of Albert Einstein, Thomas Edison, and Marie and Pierre Curie, for developing novel meth- ods to model complex engineering systems in structural dynamics, acoustics, fluid mechanics, and electromechanical systems. In addition, he received the Pendray Aerospace Literature Award from the AIAA in 1995 for his seminal contributions to perturbation methods, nonlinear dynamics, acoustics, and boundary-layer transition. The American Society of Mechanical Engineers ASME recognized him with the ASME J. P. Den Hartog Award in 1996 in recognition of lifetime contributions to the teaching and practice of vibration engineering. In 2005, Nayfeh was honored by ASME as the first recipient of the Lyapunov Award for his lifelong contributions to the field of nonlinear dynamics, and in 2008, Nayfeh received the Academy Gold Medal of Honor from the Academy of Transdisciplinary Learning and Advanced Studies. That same year, the ASME named him the first recipient of the Tom Caughey Award and he received three honorary doctorates from the Politechnika Szczecinska, of Poland; the Technical University of Munich, Germany; and the Marine Technical University of St. Petersburg, Russia.

Indeed, the life journey of Ali Nayfeh draws a striking picture of a true warrior who never gave up on his dream of seeking higher education and acquiring knowledge, despite the poverty and harsh difficulties. Anyone who has met Dr. Nayfeh knows well his inexhaustible energy and deep desire for knowledge; and more importantly, his passion to share and spread his knowledge with others. Nayfeh has left behind an amazing journey that inspires many generations and a legacy that will last for a long time. He was a brilliant scientist, a distinguished teacher, an inspiring motivator, a great community leader, and an amazing and lovely human. He will be truly and deeply missed. 